\title{
Recent advances in the approach to hepatopulmonary syndrome and portopulmonary hypertension
}

\author{
S. Raevens' ${ }^{1}$, A. Geerts ${ }^{1}$, L. Devisscher ${ }^{1,2}$, H. Van Vlierberghe' ${ }^{1}$, C. Van Steenkiste ${ }^{1}$, I. Colle \\ Hepatology Research Unit, Ghent University, Ghent, Belgium , (2) Department of Basic and Applied Medical Sciences, Gut-Liver Immunopharmacology Unit, Ghent \\ University, Ghent, Belgium.
}

\begin{abstract}
Liver disease, cirrhosis and portal hypertension can be complicated by pulmonary vascular disease, which may affect prognosis and influence liver transplantation (LT) candidacy. Pulmonary vascular complications comprise hepatopulmonary syndrome (HPS) and portopulmonary hypertension (POPH). Although these two conditions develop on a same background and share a common trigger, pulmonary responses are distinct and occur at different anatomical sites of the pulmonary circulation. HPS affects $10-30 \%$ of patients referred for LT, and is characterized by gas exchange abnormalities due to pulmonary vasodilation and right-to-left shunting. POPH occurs in 5\%, and is defined by pulmonary arterial hypertension due to increased pulmonary vascular resistance, which leads to hemodynamic failure. Even though HPS and POPH may have a substantial negative impact on survival, both entities are clinically underrecognized and frequently misdiagnosed. Without intervention, the 5-year survival rate is $23 \%$ in HPS and $14 \%$ in POPH. Their presence should be actively sought by organized screening in patients presenting with dyspnea and in all patients on the waitlist for LT, also because clinical symptoms are commonly non-specific or even absent. LT may lead to resolution, however, advanced stages of either HPS or POPH may jeopardize safe and successful LT. This implicates the need of proper identification of HPS and POPH cases, as well as the need to be able to successfully 'bridge' patients to LT by medical intervention. A review article on this topic has been published in this journal in 2007 (1). This updated review focuses on recent advances in the diagnosis and management of these 2 liver-induced pulmonary vascular disorders and incorporates results from our recent work. (Acta gastroenterol. belg., 2021, 84, 95-99).
\end{abstract}

Keywords : liver disease, cirrhosis, portal hypertension, pulmonary vascular complications.

Abbreviations : LT, liver transplantation; HPS, hepatopulmonary syndrome ; POPH, portopulmonary hypertension ; IPVDs, intrapulmonary vascular dilations ; TTE, transthoracic echocardiography; MAA, macroaggregated albumin; $\mathrm{PH}$, portal hypertension; PAH, pulmonary artery hypertension; RHC, right heart catheterization; sPAP, systolic pulmonary artery pressure; mPAP, mean pulmonary artery pressure; $\mathrm{SaO}_{2}$, oxygen saturation; CBDL, common bile duct ligation; ET-1, endothelin-1 ; eNOS, endothelial nitric oxide synthase ; $\mathrm{NO}$, nitric oxide; $\mathrm{TNF} \alpha$, tumor necrosis factor alpha; $\mathrm{CO}$, carbon monoxide; VEGF, vascular endothelial growth factor ; PDGF, platelet-derived growth factor; PIGF, placental growth factor ; AT2, alveolar type II ; SE, standard exception ; PVR, pulmonary vascular resistance; ETR, endothelin receptor; PDE-5, phosphodiesterase type V.

\section{Introduction}

HPS is characterized by a disturbed gas exchange resulting from intrapulmonary vascular dilations (IPVDs)
Table 1. - Diagnostic criteria and staging of severity of HPS

\begin{tabular}{|c|c|}
\hline 1. Presence & \\
\hline 2. Evidence & \\
\hline 3. $\mathrm{P}(\mathrm{A}-\mathrm{a}) \mathrm{O}_{2}$ & $0 \mathrm{mmHg}$ if age $\geq 65$ ) \\
\hline Stage & $\mathrm{PaO}_{2}$ \\
\hline Mild & $\geq 80 \mathrm{mmHg}$ \\
\hline Moderate & $60-79 \mathrm{mmHg}$ \\
\hline Severe & $50-59 \mathrm{mmHg}$ \\
\hline Very severe & $<50 \mathrm{mmHg}$ \\
\hline
\end{tabular}

HPS, hepatopulmonary syndrome ; IPVDs, intrapulmonary vascular dilations.

Table 2. - Diagnostic criteria and staging of severity of POPH

\begin{tabular}{l|}
\hline 1. Presence of portal hypertension \\
2. $\mathrm{mPAP}>25 \mathrm{mmHg}$ \\
\begin{tabular}{l|c|} 
3. PCWP $<15 \mathrm{mmHg}$ \\
4. PVR $>240$ dyn.s $/ \mathrm{cm}^{5}$ & $m P A P$ \\
\hline Stage & $>25-<35 \mathrm{mmHg}$ \\
Mild & $\geq 35-<45 \mathrm{mmHg}$ \\
Moderate & $\geq 45 \mathrm{mmHg}$ \\
Severe &
\end{tabular}
\end{tabular}

$\mathrm{POPH}$, portopulmonary hypertension ; mPAP, mean pulmonary artery pressure ; PCWP, pulmonary capillary wedge pressure ; PVR, pulmonary vascular resistance.

and arteriovenous shunting (Table 1). Diagnosis is made by documenting gas exchange disturbances on arterial blood gas (ABG) and IPVDs by microbubble transthoracic echocardiography (TTE) or 99m-Technetium-labeled macroaggregated albumin (MAA) scan (2). HPS severity is classified based on $\mathrm{PaO}_{2}$ measurements (Table 1). POPH is defined as the presence of pulmonary artery hypertension $(\mathrm{PAH})$ that evolves as a consequence of portal hypertension $(\mathrm{PH})$. Obstruction of pulmonary flow may progress to right heart failure. Diagnosis is made by right heart catheterization (RHC) (Table 2) (2). Screening is performed by TTE, which allows early detection of elevated systolic pulmonary artery pressure (sPAP). Every suspicion of POPH on TTE should be confirmed by RHC for direct measurement of pulmonary

Correspondence to : Sarah Raevens, MD, PhD, Department of Gastroenterology and Hepatology, Ghent University Hospital, Building K12 First Floor IE, Corneel Heymanslaan 10, 9000 Ghent, Belgium. Phone : +32 933253 01, Fax : +32 9 3324984 .

E-mail : sarah.raevens@ugent.be

Submission date : 01/12/2020

Acceptance date : 06/12/2020 
hemodynamics. Severity of POPH is classified based on the mean pulmonary artery pressure (mPAP) (Table 2).

\section{Recent advances in hepatopulmonary syndrome}

\section{Screening and diagnosis}

The majority of HPS patients is either asymptomatic or present with insidious onset of dyspnea. ABG and microbubble TTE or 99m-Technetium-labeled MAA scan to detect IPVDs represent the gold standard for diagnosis, although are complex, quite invasive, time consuming and expensive to include in screening programs or repeated follow-up. More simple and noninvasive screening methods are needed to facilitate the screening process. Currently, oxygen saturation $\left(\mathrm{SaO}_{2}\right)$ measurement is the only available screening tool for HPS, with a cutoff of $94-96 \%$ for further diagnostic testing. Earlier reports have shown that pulse oximetry is feasible to detect severe forms of HPS (3). However, due to the shape of the oxyhemoglobin dissociation curve, small changes in $\mathrm{SaO}_{2}$ may be associated with large changes in $\mathrm{PaO}_{2}$, and therefore, pulse oximetry should be interpreted with caution $(4,5)$. Forde et al. recently reported that pulse oximetry represents a poor screening test for HPS in LT candidates, and showed that a $\mathrm{SaO}_{2}$ of $94 \%$ provides poor sensitivity $(22.1 \%)$ and specificity (89.8\%) to detect severe HPS (5). These issues stimulated research on biomarkers for HPS.

Bacterial translocation with monocyte adherence in the lung has been reported to drive experimental HPS, causing downstream production of angiogenesis ensues, which are responsible for IPVDs (summarized below and (6)). Angiogenesis, the process of formation of new blood vessels, has been largely studied as a main driver in the development of liver disease, cirrhosis, portal hypertension and complications (7-9). Given their pathogenic importance in the development of intrapulmonary shunt formation in HPS, markers of endothelial dysfunction and angiogenesis have been studied for their potential to differentiate between cirrhotic patients with and without HPS. Vascular cellular adhesion molecule 1 (with an area under the curve (AUC) of $0.93,95 \%$ CI : 0.85 to 1 ) and of von Willebrand Factor (AUC of $0.84,95 \%$ CI : 0.77-0.91) have been identified as potential predictors for HPS, which perform better than $\mathrm{SaO}_{2}(\mathrm{AUC} 0.74,95 \%$ CI : 0.65-0.83) $(10,11)$. Although the performance of these biomarkers needs validation in a larger group of patients prior to clinical application, the obtained data suggest that the use of these biomarkers could facilitate the identification of HPS among patients with liver cirrhosis and LT candidates.

\section{Pathogenesis and potential targets for therapy}

Several animal models have been tested for their ability to induce the pulmonary vascular and gas exchange abnormalities of human HPS. For a long time,

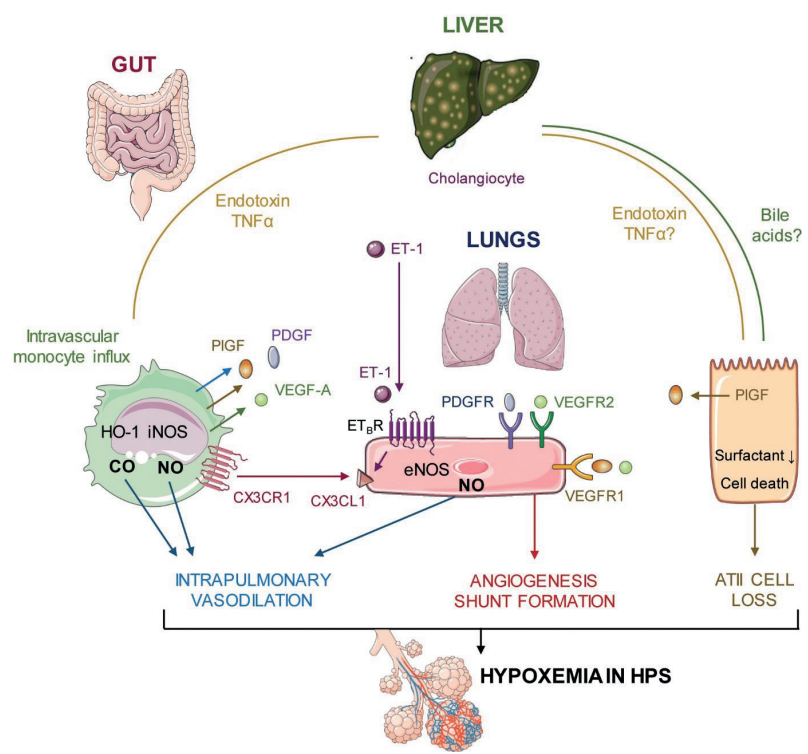

Figure 1. - Current understanding of HPS pathogenesis. Salient features of experimental HPS induced by CBDL include pulmonary ET-1-induced endothelial dysfunction, monocyte infiltration, angiogenesis and AT2 cell dysfunction. These overlapping events drive the development of hypoxemia and represent potential therapeutic targets. (reproduced from (6)).

Abbreviations: HPS, hepatopulmonary syndrome; CBDL, common bile duct ligation ; ET-1, endothelin-1 ; AT2, alveolar type II ; HO-1, heme oxygenase 1; CO, carbon monoxide; iNOS, inducible nitric oxide synthase ; NO, nitric oxide ; PlGF, placental growth factor ; VEGF, vascular endothelial growth factor; PDGF, platelet-derived growth factor; PDGFR, platelet-derived growth factor receptor; VEGFR, vascular endothelial growth factor receptor; CX3CR1, fraktalkine receptor; $\mathrm{CX} 3 \mathrm{CL} 1$, fraktalkine; $\mathrm{ET}_{\mathrm{B}} \mathrm{R}$, endothelin $\mathrm{B}$ receptor; eNOS, endothelial nitric oxide synthase; TNF $\alpha$, tumor necrosis factor alpha.

common bile duct ligation (CBDL) in the rat was the only established experimental model (12). Recently, a mouse model for HPS has been validated (13). These animal models provided valuable insight into the pathogenesis of the disease. Briefly summarized, a complex interaction between pulmonary endothelial cells, monocytes and the respiratory epithelium underlies pulmonary microvascular alterations, responsible for impaired oxygenation and hypoxemia (Figure 1) (6). Prominent changes following CBDL include an increase in circulating endothelin-1 (ET-1), bile acid load and altered bile acid composition, increased serum levels of endotoxins and tumor necrosis factor alpha $(\mathrm{TNF} \alpha)$, increased intestinal permeability and signs of pulmonary inflammation. Circulating endotoxins enter the pulmonary circulation, where they induce local production of chemotactic factors, guiding monocyte recruitment. These monocytes secrete vasodilating factors (e.g. carbon monoxide (CO) and NO), which lead to IPVDs, and pro-angiogenic mediators (e.g. vascular endothelial growth factor (VEGF), platelet-derived growth factor (PDGF), placental growth factor (PIGF) and others), which stimulate angiogenesis, which in turn lead to shunt formation. Recent studies support that also ventilation defects, caused by increased apoptosis 
of alveolar type II (AT2) cells, may contribute to gas exchange abnormalities in HPS.

For a more detailed overview of molecular mechanisms involved in the pathogenesis of HPS, translational aspects derived from experimental studies, and references, we refer to our manuscript published in Hepatology in 2018 (6).

\section{Management and treatment options}

HPS is associated with worse quality of life and increased mortality (14). Despite significant progress in HPS research, effective pharmacological therapies are currently lacking. Novel treatments are needed, that either resolve and cure HPS or slow down its progression to secure successful LT. Although treatment with sorafenib has been shown to be beneficial in HPS rats (15), results from a recently published randomized controlled trial were disappointing: sorafenib did not change the $\mathrm{P}(\mathrm{A}-\mathrm{a}) \mathrm{O}_{2}$ gradient or other disease markers after 3 months of therapy (16). Also, based on clinical experience, the risk of toxicity in this specific patient population is expected to be high, thereby limiting its use. As PIGF - a member of the VEGF family and recently been shown to be involved in experimental HPS development - is only minimally expressed in healthy tissue, the risk of off-target effects expected with PIGF inhibitors is low. Therefore, targeting PlGF may be a more attractive therapeutic strategy. However, based on the number of potential mechanisms of HPS, targeting multiple pathways may be needed in future trials.

Currently, LT is the only curative treatment option for HPS (2). Five-year survival of $76 \%$ has been observed in transplanted patients with HPS, which is comparable to post-LT outcome in patients without HPS, versus only $23 \%$ in HPS patients who were not transplanted (17). As hypoxemia in HPS is generally progressive, mortality is highest in advanced stages, and no correlation has been found between HPS severity and the severity of the underlying liver disease, a standard exception (SE) policy has been established to prioritize patients with severe HPS $\left(\mathrm{PaO}_{2}<60 \mathrm{mmHg}\right)$ (2). Substantially improved long-term survival has been observed since the MELD exception era (18). Complete resolution of HPS

Table 3. - Key points in the management of HPS and POPH

\begin{tabular}{|l|}
\hline HPS \\
- No effective medical treatments are available \\
- LT is curative and HPS represents an indication for LT \\
- MELD SE applies for severe $\mathrm{HPS}\left(\mathrm{PaO}_{2}<60 \mathrm{mmHg}\right)$ \\
\hline POPH \\
- Vasomodulator therapy improves pulmonary hemodynamics and \\
prognosis and represents the mainstay of treatment \\
- POPH itself does not represent an indication for LT \\
- LT can be considered in a selected subpopulation who have a clear \\
primary hepatic indication for LT and who achieved sufficient \\
hemo-dynamic response after vasomodulator therapy
\end{tabular}

HPS, hepatopulmonary syndrome ; POPH, portopulmonary hypertension ; LT, liver transplantation ; SE, standard exception. following LT occurs in $>80 \%$ of cases, mostly within 6 to 12 months (19). In 2014, Goldberg et al. evaluated the post-LT outcomes in HPS and found similar postLT survival in HPS and non-HPS patients (20). A recent analysis from the Eurotransplant registry reported similar overall mortality between LT candidates with and without HPS (21).

Keypoints in HPS management are summarized in Table 3.

\section{Recent advances in portopulmonary hypertension}

\section{Screening and diagnosis}

The most common symptom in patients with POPH is progressive dyspnea on exertion, which is non-specific and frequently reported by cirrhotic patients. In most cases, screening TTE provides the first sign leading to the diagnosis, however, is not accurate enough to make the diagnosis. Obstruction of pulmonary flow due to vasoconstriction, intima and media proliferation and vascular remodeling increases pulmonary vascular resistance (PVR), which is the primary criterion $\mathrm{POPH}$ diagnosis is based on. POPH diagnosis relies on RHC with proof of increased mPAP and PVR. However, pulmonary hemodynamic measurements are frequently misinterpreted, and as such, POPH is often not accurately recognized (22). In this context, POPH screening with TTE needs to unequivocally provide clues that warrant further investigation. Despite well-defined criteria for $\mathrm{POPH}$, there is still considerable variation among tertiary referral centers concerning which patients should proceed to RHC to make the definite diagnosis. The debate about the cutoff value of estimated sPAP triggering the need of RHC is still a work in progress. While a cutoff of 50 $\mathrm{mmHg}$ reliably detects moderate-severe POPH (23), a lower cutoff of $30 \mathrm{mmHg}$ is able to detect all forms of POPH, including the mild ones $(24,25)$. The high number of false positives associated with lower sPAP cutoffs represents an important drawback. We aimed to refine the current TTE screening algorithm by retrospectively analyzing a more appropriate referral point (25). We determined $38 \mathrm{mmHg}$ as the most accurate sPAP cutoff value to detect all forms of POPH (specificity of $83 \%$, negative predictive value of $100 \%$ ) (25). Application of this cutoff would reduce the number of unneeded RHC's (25). Increased PVR in POPH directly results in right heart dysfunction. Taking this into consideration, we were able to further improve the accuracy of the $38 \mathrm{mmHg}$ cutoff by adding the presence of right ventricular dilatation. These criteria yield a sensitivity of $100 \%$, specificity of $93 \%$, and negative predictive value of $100 \%$ (25). This study was the first report that underscores the importance of including cardiac function into POPH screening.

\section{Management and treatment options}

Understanding outcomes in patients with POPH has been confounded by small series published before current 
PAH-specific therapies became available and prior to the current experience with LT. Swanson et al. reported a mean survival of 15 months and a 5-year survival of $14 \%$ in patients with POPH denied LT and not treated with the currently available agents (26).

Medical treatment consists of vasomodulators, largely extrapolated from studies in $\mathrm{PAH}$, where beneficial effects on hemodynamics and prognosis have been found. The main drug categories comprise prostacyclins, endothelin receptor (ETR) antagonists and phosphodiesterase type V (PDE-5) inhibitors. Initially, intravenous epoprostenol was the best-studied drug in POPH. Although its efficacy in improving hemodynamics and exercise capacity has been reported in small studies, this treatment option has important drawbacks with regard to safety. During the last several years, experience has been gained with oral treatments.

Both progressive right heart failure or complications of liver disease may cause death in those with POPH not undergoing LT. However, the outcomes of LT in the setting of POPH may be unpredictable and the factors that determine whether POPH resolves are not fully defined. It is clear that advanced POPH is associated with markedly increased operative risk. Specifically, moderate-severe POPH (mPAP >35 mmHg) substantially increases mortality risk and severe POPH (mPAP $>45 \mathrm{mmHg}$ ) is considered an absolute contraindication to LT (27). With the recent availability of potent vasomodulators, effective improvement in pulmonary hemodynamics is feasible and several centers have reported safe and successful LT in those with adequate control (mPAP $<35 \mathrm{mmHg}$ ). Therefore, a logical strategy includes sequential therapy consisting of adequate control of pulmonary hemodynamics with vasomodulators followed by consideration of LT in appropriate candidates to resolve underlying liver disease. A recent metaanalysis evaluated pulmonary hemodynamics and outcomes in POPH patients receiving no treatment, treatment with vasomodulators, LT, or vasomodulators followed by LT (28). Both vasomodulator therapy and vasomodulator therapy followed by LT significantly improved pulmonary hemodynamics and prognosis. In all studies where LT was considered, the decision to proceed with transplant was made only in those with a primary hepatic indication for LT who also achieved a sufficient hemodynamic response after vasomodulator therapy. Pooled estimates for 1- and 3-years postdiagnosis survival were comparable in POPH patients treated with vasomodulators alone and vasomodulators followed by LT. However, in the selected subpopulation of cases where LT was indicated based on severity of liver disease and where LT was considered safe and feasible, treatment with vasomodulators and LT confers better prognosis than vasomodulators alone. Accordingly, MELD standard exception for POPH is available to gain priority for LT. Criteria include lowering mPAP to $<25$ $35 \mathrm{mmHg}$ in those with previously established POPH.
Keypoints in POPH management are summarized in Table 3 .

\section{Conclusion}

In the past several decades, the clinical importance of liver-lung interactions in the context of chronic liver disease, and specifically the entities of HPS and POPH, have become more recognized. Severity and natural history of pulmonary abnormalities may present increased mortality risk, and their potential resolution following LT suggests that these disorders may be appropriate indications for LT in selected cases and should merit higher LT priority to prevent mortality. Therefore, prompt identification of HPS and POPH cases among our LT candidates is of utmost importance.

\section{Conflict of interest}

The authors do not report any disclosures.

\section{References}

1. COLLE I, VAN STEENKISTE C, GEERTS A, VAN VLIERBERGHE H. Hepatopulmonary syndrome and portopulmonary hypertension : what's new? Acta Gastro-enterol. Belg., 2007 Apr, 70(2) : 203-209.

2. KROWKA MJ, FALLON MB, KAWUT SM, FUHRMANN V, HEIMBACH JK, RAMSAY MA, et al. International Liver Transplant Society Practice Guidelines: Diagnosis and Management of Hepatopulmonary Syndrome and Portopulmonary Hypertension. Transplantation, 2016 Jul, 100(7) : 14401452 .

3. ARGUEDAS MR, SINGH H, FAULK DK, FALLON MB. Utility of pulse oximetry screening for hepatopulmonary syndrome. Clin. Gastroenterol. Hepatol., 2007 Jun, 5(6) : 749-754.

4. RAEVENS S, COLLE I, GEERTS A, VAN VLIERBERGHE H. Why Pulse Oximetry Is Inaccurate in Liver Cirrhosis : Ancient Knowledge. Hepatology, 2019 Jan, 69(1) : 462-463

5. FORDE KA, FALLON MB, KROWKA MJ, SPRYS M, GOLDBERG DS, KROK KL, et al. Pulse Oximetry Is Insensitive for Detection of Hepatopulmonary Syndrome in Patients Evaluated for Liver Transplantation. Hepatology, 2019 Jan, 69(1) : 270-281.

6. RAEVENS S, FALLON MB. Potential clinical targets in hepatopulmonary syndrome : lessons from experimental models. Hepatology, 2018 Nov, 68(5) : 2016-2028.

7. FERNANDEZ M, SEMELA D, BRUIX J, COLLE I, PINZANI M, BOSCH J. Angiogenesis in liver disease. J. Hepatol., 2009 Mar, 50(3) : 604-620.

8. CURAKOVA RE, GENADIEVA-DIMITROVA M, CALOSKA-IVANOVA V, MISEVSKI J. Von-Willebrand factor as a predictor of three-month mortality in patients with liver cirrhosis compared to MELD score. Acta Gastroenterol. Belg., 2019 Oct, 82(4) : 487-493.

9. LEFERE S, DEVISSCHER L, GEERTS A. Angiogenesis in the progression of non-alcoholic fatty liver disease. Acta Gastroenterol. Belg., 2020 Apr, 83(2) : 301-307.

10. RAEVENS S, COULON S, VAN STEENKISTE C, COLMAN R, VERHELST X, VAN VLIERBERGHE H, et al. Role of angiogenic factors/ cell adhesion markers in serum of cirrhotic patients with hepatopulmonary syndrome. Liver Int., 2015 May, 35(5) : 1499-507.

11. HORVATITS T, DROLZ A, ROEDL K, HERKNER H, FERLITSCH A, PERKMANN T, et al. Von Willebrand factor antigen for detection of hepatopulmonary syndrome in patients with cirrhosis. J. Hepatol., $2014 \mathrm{Sep}$, 61(3) : 544-549.

12. FALLON MB, ABRAMS GA, MCGRATH JW, HOU Z, LUO B. Common bile duct ligation in the rat: a model of intrapulmonary vasodilatation and hepatopulmonary syndrome. Am. J. Physiol., 1997 Apr, 272(4 Pt 1) : G779-G784.

13. RAEVENS S, GEERTS A, PARIDAENS A, LEFERE S, VERHELST X, HOORENS A, et al. Placental growth factor inhibition targets pulmonary angiogenesis and represents a novel therapy for hepatopulmonary syndrome in mice. Hepatology, 2018 Aug, 68(2) : 634-651. 
14. FALLON MB, KROWKA MJ, BROWN RS, TROTTER JF, ZACKS S, ROBERTS KE, et al. Impact of hepatopulmonary syndrome on quality of life and survival in liver transplant candidates. Gastroenterology, 2008 Oct, 135(4) : 1168-1175.

15. CHANG CC, CHUANG CL, LEE FY, WANG SS, LIN HC, HUANG HC, et al. Sorafenib treatment improves hepatopulmonary syndrome in rats with biliary cirrhosis. Clin. Sci. (Lond), 2013 Apr, 124(7) : 457-466.

16. KAWUT SM, ELLENBERG SS, KROWKA MJ, GOLDBERG D, VARGAS H, KOCH D, et al. Sorafenib in Hepatopulmonary Syndrome : A Randomized, Double-Blind, Placebo-Controlled Trial. Liver Transpl., 2019 Aug, 25(8) : 1155-1164.

17. SWANSON KL, WIESNER RH, KROWKA MJ. Natural history of hepatopulmonary syndrome: Impact of liver transplantation. Hepatology, 2005 May, 41(5) : 1122-1129.

18. IYER VN, SWANSON KL, CARTIN-CEBA R, DIERKHISING RA, ROSEN CB, HEIMBACH JK, et al. Hepatopulmonary syndrome : favorable outcomes in the MELD exception era. Hepatology, 2013 Jun, 57(6) : 2427 2435.

19. PASCASIO JM, GRILO I, LOPEZ-PARDO FJ, ORTEGA-RUIZ F, TIRADO JL, SOUSA JM, et al. Prevalence and severity of hepatopulmonary syndrome and its influence on survival in cirrhotic patients evaluated for liver transplantation. Am. J. Transplant., 2014 Jun, 14(6) : 1391-1399.

20. GOLDBERG DS, KROK K, BATRA S, TROTTER JF, KAWUT SM, FALLON MB. Impact of the hepatopulmonary syndrome MELD exception policy on outcomes of patients after liver transplantation : an analysis of the UNOS database. Gastroenterology, 2014 May, 146(5) : 1256-1265.

21. RAEVENS S, ROGIERS X, GEERTS A, VERHELST X, SAMUEL U, VAN ROSMALEN M, et al. Outcome of liver transplantation for hepatopulmonary syndrome : a Eurotransplant experience. Eur. Respir. J., 2019 Feb, 53(2)
22. GOLDBERG DS, BATRA S, SAHAY S, KAWUT SM, FALLON MB MELD Exceptions for Portopulmonary Hypertension : Current Policy and Future Implementation. Am. J. Transplant., 2014 Sep, 14(9) : 2081-2087.

23. KROWKA MJ, SWANSON KL, FRANTZ RP, MCGOON MD, WIESNER RH. Portopulmonary hypertension: Results from a 10-year screening algorithm. Hepatology, 2006 Dec, 44(6) : 1502-1510.

24. COLLE IO, MOREAU R, GODINHO E, BELGHITI J, ETTORI F, COHENSOLAL A, et al. Diagnosis of portopulmonary hypertension in candidates for liver transplantation : a prospective study. Hepatology, $2003 \mathrm{Feb}, 37(2)$ : 401-409.

25. RAEVENS S, COLLE I, REYNTJENS K, GEERTS A, BERREVOET F, ROGIERS X, et al. Echocardiography for the detection of portopulmonary hypertension in liver transplant candidates : an analysis of cutoff values. Liver Transpl., 2013 Jun, 19(6) : 602-610.

26. SWANSON KL, WIESNER RH, NYBERG SL, ROSEN CB, KROWKA MJ. Survival in portopulmonary hypertension: Mayo Clinic experience categorized by treatment subgroups. Am. J. Transplant., 2008 Nov, 8(11) : 2445-2453.

27. KROWKA MJ, PLEVAK DJ, FINDLAY JY, ROSEN CB, WIESNER RH, KROM RA. Pulmonary hemodynamics and perioperative cardiopulmonaryrelated mortality in patients with portopulmonary hypertension undergoing liver transplantation. Liver Transpl., 2000 Jul, 6(4) : 443-450.

28. DEROO R, TREPO E, HOLVOET T, DE PAUW M, GEERTS A, VERHELST $\mathrm{X}$, et al. Vasomodulators and liver transplantation for portopulmonary hypertension: evidence from a systematic review and meta-analysis. Hepatology, 2020 Nov, 72(5) : 1701-1716. 